\section{RMD Open}

Rheumatic \&

Musculoskeletal Diseases

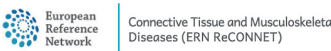

\title{
Sjögren's syndrome: state of the art on clinical practice guidelines
}

\author{
Vasco C Romão, ${ }^{1}$ Rosaria Talarico, ${ }^{2}$ Carlo Alberto Scirè, ${ }^{3}$ Ana Vieira, ${ }^{4}$ \\ Tobias Alexander, ${ }^{5}$ Chiara Baldini, ${ }^{2,6}$ Jacques-Eric Gottenberg, ${ }^{7}$ Heidi Gruner, ${ }^{8}$ \\ Eric Hachulla, ${ }^{9}$ Luc Mouthon, ${ }^{10}$ Martina Orlandi, ${ }^{11}$ Cristina Pamfil, ${ }^{12}$ \\ Marc Pineton de Chambrun, ${ }^{13}$ Marco Taglietti, ${ }^{14}$ Natasa Toplak, ${ }^{15}$ Paul van Daele, ${ }^{16}$ \\ Jacob M van Laar, ${ }^{17}$ Stefano Bombardieri, ${ }^{18}$ Matthias Schneider, ${ }^{19}$ \\ Vanessa Smith, ${ }^{20}$ Maurizio Cutolo, ${ }^{21}$ Marta Mosca, ${ }^{2,6}$ Xavier Mariette ${ }^{22}$
}

To cite: Romão VC, Talarico R, Scirè CA, et al. Sjögren's syndrome: state of the art on clinical practice guidelines. RMD Open 2018;4:e000789. doi:10.1136/ rmdopen-2018-000789

Received 6 August 2018 Revised 12 September 2018 Accepted 13 September 2018
Check for updates

\section{(C) Author(s) (or their} employer(s)) 2018. Re-use permitted under CC BY-NC. No commercial re-use. See rights and permissions. Published by BMJ.

For numbered affiliations see end of article.

Correspondence to Professor Xavier Mariette; xavier.mariette@aphp.fr

\section{ABSTRACT}

Sjögren's syndrome (SS) is a complex autoimmune rheumatic disease that specifically targets salivary and lachrymal glands. As such, patients typically had ocular and oral dryness and salivary gland swelling. Moreover, skin, nasal and vaginal dryness are frequently present. In addition to dryness, musculoskeletal pain and fatigue are the hallmarks of this disease and constitute the classic symptom triad presented by the vast majority of patients. Up to $30 \%$ to $50 \%$ of patients with SS may present systemic disease; moreover, there is an increased risk for the development of non-Hodgkin's lymphoma that occurs in a minority of patients. The present work was developed in the framework of the European Reference Network (ERN) dedicated to Rare and Complex Connective Tissue and Musculoskeletal Diseases (ReCONNET). In line with its goals of aiming to improve early diagnosis, treatment and care of rare connective and musculoskeletal diseases, ERN-ReCONNET set to review the current state of clinical practice guidelines (CPGs) in the rare and complex connective tissue diseases of interest of the network. Therefore, the present work was aimed at providing a state of the art of CPGs for SS.

\section{INTRODUCTION}

Sjögren's syndrome (SS) is a complex autoimmune rheumatic disease that specifically targets salivary and lachrymal glands. ${ }^{1}$ As such, patients typically had ocular and oral dryness and salivary gland swelling. Moreover, skin, nasal and vaginal dryness are frequently present. In addition to dryness, musculoskeletal pain and fatigue are the hallmarks of this disease and constitute the classic symptom triad presented by the vast majority of patients. Up to $30 \%$ to $50 \%$ of patients with SS may present systemic disease affecting several organ compartments, such as articular, pulmonary, neurological or kidney involvement. ${ }^{12}$ There is an increased risk for the development of non-Hodgkin's

\section{Key messages}

What is already known about this subject?

- Good quality CPGs on diagnosis and management of SS have been recently published.

What does this study add?

- A number of unmet needs for SS were identified by patients and clinicians.

How might this impact on clinical practice?

- There is a major gap in effective specific therapies capable of decisively impacting on the outcomes of SS.

lymphoma that occurs in a minority of patients. $^{12}$

The diagnosis of SS is made on the basis of medical history, physical examination, specific ocular and oral evaluation, blood tests and salivary gland assessment (biopsy and ultrasound). ${ }^{12}$ Treatment focuses on relieving symptoms by using artificial tears and saliva, sugar-free candy and secretagogue drugs such as pilocarpine or cevimeline. ${ }^{23}$ General symptoms such as pain and fatigue are frequently treated with hydroxychloroquine. Specific extraglandular involvement may require immunosuppressive drugs. ${ }^{3}$ Novel biological drugs are in the pipeline for the treatment of the disease. ${ }^{4}$

As a complex multisystemic disease, specialised multidisciplinary care is recommended for patients with SS. Also, this highlights the need for disease-specific clinical practice guidelines (CPGs) that set the standards for the management of SS in terms of diagnosis, monitoring, treatment and prognosis. These CPGs are key tools that can be used in routine clinical care by physicians that directly deal with and manage patients with 
SS (rheumatology, ophthalmology, oral medicine and other specialties, depending on organ involvement) and general practitioners that encounter undiagnosed patients with typical SS complaints. The universal availability and widespread use of CPGs contributes to improvement and standardisation of care, ultimately benefiting patients with SS. Moreover, CPGs are important to define the areas with poorer evidence, and more unmet needs that should constitute the main focus of future research.

The present work was developed in the framework of the European Reference Network $(\mathrm{ERN})^{56}$ dedicated to Rare and Complex Connective Tissue and Musculoskeletal Diseases (ReCONNET) ${ }^{7}$ In line with its goals of aiming to improve early diagnosis, treatment and care of rare connective and musculoskeletal diseases, ERN-ReCONNET set to review the current state of CPGs in the rare and complex connective tissue diseases (CTDs) of interest of the network. A systematic literature review (SLR) of current evidence-based medicine (EBM) CPGs was conducted for each disease, coordinated by junior and senior disease coordinators (DCs), and the results were presented and discussed in ERN-ReCONNET plenary meetings. The present narrative review reports on the SLR performed for CPGs related to diagnosis, monitoring and treatment of SS.

\section{METHODS}

We carried out a systematic search in Medline (PubMed) and Embase based on controlled terms (MeSH and Emtree) and keywords of this disease (SS) and publication type (CPGs). We reviewed all the published articles in order to identify existing CPGs on diagnosis, monitoring and treatment, according to the ${ }^{8}$ definition: clinical practice guidelines are statements that include recommendations intended to optimise patient care that are informed by a systematic review of evidence and an assessment of the benefits and harms of alternative care options. ${ }^{8}$

The DCs of the ERN-ReCONNET for SS have assigned the work on CPGs to the 14 healthcare providers (HCPs) involved, from seven European countries (France, Germany, Italy, The Netherlands, Portugal, Romania and Slovenia). Moreover, in order to complement the list of guidelines provided by Medline and Embase search, the group also performed a hand search on a number of national and international websites relevant in the field of SS and/or clinical guidance. After a first screening among papers included in the final list (systematic search+hand search) based on title and abstract, full text evaluation was conducted to select EBM guidelines. A general assessment of the CPGs was performed based on the Appraisal of Guidelines for Research \& Evaluation II instrument ${ }^{9}$ not for formal appraisal but only to inform discussion. The final goal was to perform a broad assessment of current guidelines on SS, with input of all HCPs, that would serve as basis to define unmet needs. For this matter, a discussion group was set for the evaluation of the existing CPGs and identification of unmet needs.
The search strategy employed was as follows «Medline (PubMed): ("sjogren's syndrome"[MeSH Terms] OR ("sjogren's"[All Fields] AND "syndrome"[All Fields]) OR "sjogren's syndrome" [All Fields]) AND ("Practice Guideline"'[Publication Type] OR "Practice Guidelines As Topic"'[MeSH Terms] OR Practice Guideline[Publication Type] OR "Practice Guideline"'[Text Word] OR "Practice Guidelines"'[Text Word] OR"Guideline"'[Publication Type] OR "Guidelines As Topic"' [MeSH Terms] OR Guideline[Publication Type] OR "Guideline" [Text Word] OR "Guidelines"' [Text Word] OR "Consensus Development Conference"'[Publication Type] OR"Consensus Development Conferences As Topic"'[MeSH Terms] OR "Consensus"'[MeSH Terms] OR "Consensus"'[Text Word] OR "Recommendation"'[Text Word] OR "Recommendations"'[Text Word] OR "Best Practice"'[Text Word] OR "Best Practices"'[Text Word]). Embase: ('sjoegren syndrome'/exp OR 'sjoegren syndrome' OR 'sicca syndrome' OR 'sjoegren disease' OR 'sjogren disease' OR 'sjogren syndrome' OR 'sjogren`s syndrome') AND ('practice guideline'/exp OR 'practice guideline' OR 'practice guidelines'/exp OR 'practice guidelines' OR 'clinical practice guideline'/exp OR 'clinical practice guideline' OR 'clinical practice guidelines' / exp OR 'clinical practice guidelines' OR 'clinical practice guidelines as topic'/exp OR 'clinical practice guidelines as topic' OR 'guideline'/ exp OR 'guideline' OR 'guidelines' / exp OR 'guidelines' OR 'guidelines as topic'/exp OR 'guidelines as topic' OR 'consensus development'/exp OR 'consensus development' OR 'consensus development conference' / exp OR 'consensus development conference' OR 'consensus development conferences'/exp OR 'consensus development conferences' OR 'consensus development conferences as topic'/exp OR 'consensus development conferences as topic' OR 'consensus' / exp OR 'consensus' OR 'recommendation' OR 'recommendations') AND ([embase)]/ $\lim$ NOT ([medline) $] /$ lim»

\section{STATE OF THE ART ON CPGS}

The flow diagram adapted from the Preferred Reporting Items for Systematic Reviews and Meta-Analyses statement for the identification of EBM CPGs on SS is represented in figure $1 .^{10}$. Systematic database search identified 742 records that together with 35 records retrieved through manual search led to a total of 777 references for screening. Title and abstract screening was then conducted by HCP representatives, excluding 696 records. A total of 81 articles were eligible for full text assessment, of which 68 were excluded. Main reasons for exclusion included articles not related to SS (ie, wrong patients' population) and article type other than guidelines (ie, original research or review manuscripts). A few articles were recommendations not supported by SLR, which were thus not EBM CPGs, the main focus of the present work. Finally, six papers were excluded as duplicates. In the end, seven articles were identified as EBM CPGs and included for further analysis. 


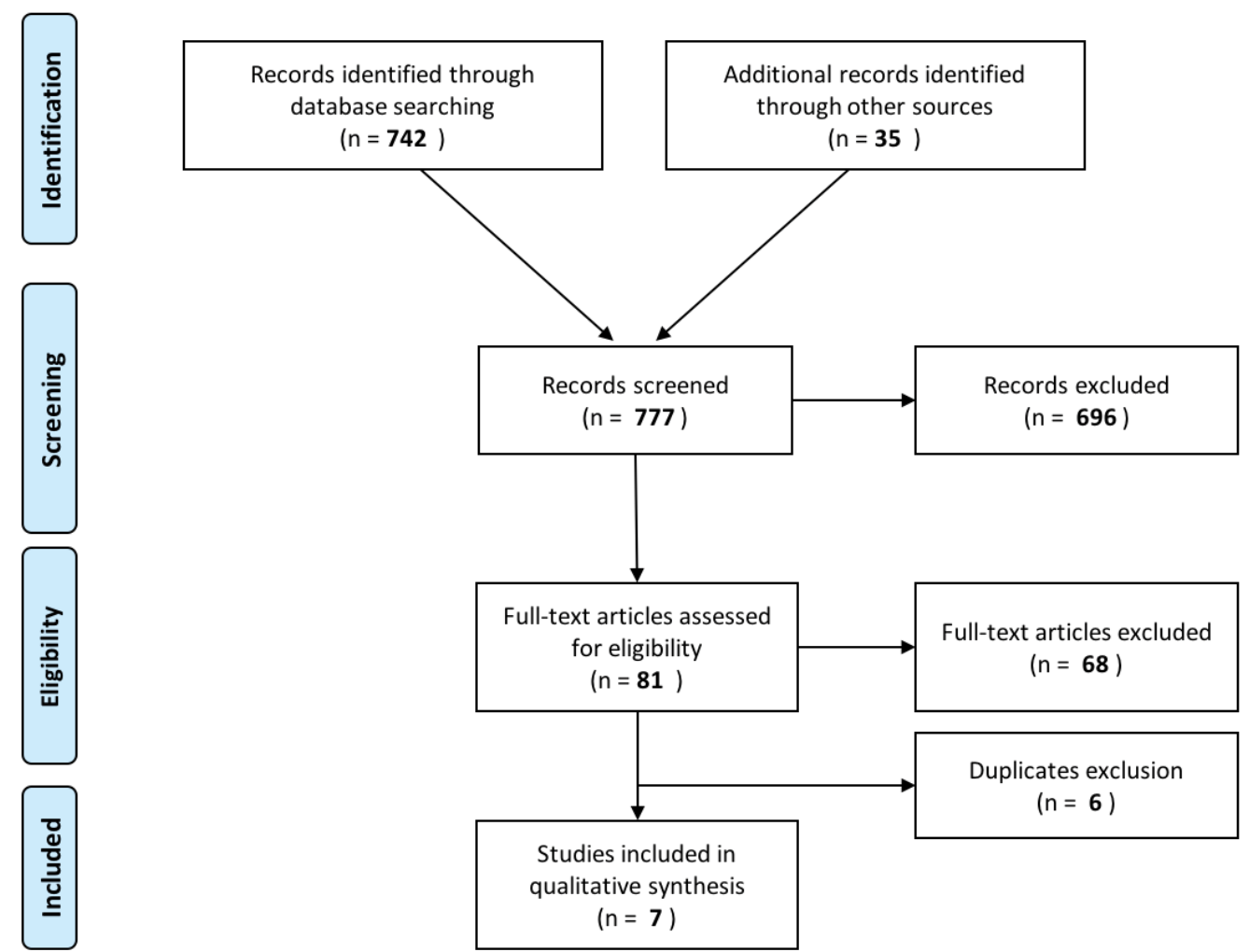

Figure 1 Flow diagram representing the search strategy for evidence-based medicine clinical practice guidelines on Sjögren's syndrome. Adapted from the Preferred Reporting Items for Systematic Reviews and Meta-Analyses statement by Moher et al. ${ }^{10}$

The major topics of the included CPGs are summarised in table 1. We found high-quality EBM up-to-date guidelines on diagnosis (specifically addressing four extraglandular domains ${ }^{11}$ ) and treatment/management (both of glandular and extraglandular manifestations ${ }^{12-14}$ that have all been recently published in the last 3 years by European (European League Against Rheumatism (EULAR) SS task force; UK), American (USA) and Latin American (Brazil) societies/organisations. All of these presented high-quality methodology, were based on a thorough SLR and presented in a clear, appropriate way, with adequate, comprehensive recommendations relevant for clinical practice. Three other guidelines provided important information on early diagnosis of $\mathrm{SS}^{15}$ or management of dryness, ${ }^{1617}$ and were evaluated as being of good overall quality, although in some instances based on a less robust methodological process. Of note, most of the analysed recommendations were often based on expert opinion, rather than solid evidence, considering the lack of highquality studies that is seen in a number of areas of interest in SS.

Common aspects focused by the majority of CPGs include: (i) the need to reinforce patient education in terms of the disease itself and general measures of symptom relief and complications prevention; (ii) the importance of collaborative multidisciplinary care in diagnosis and follow-up of patients with SS; (iii) the central role of specialised assessment of patients with SS by physicians with expertise and experience in the disease and its various aspects.
Concerning diagnosis, the EULAR SS task force has provided recommendations for an adequate description of systemic involvement in primary SS, specifically for articular, cutaneous, pulmonary and renal manifestations. ${ }^{11}$ The main goals were to provide guidance on clear-cut definitions, prevalence, clinical characteristics and diagnostic approach of each of these organ-specific extraglandular manifestations. As part of the same effort, the authors planned three other manuscriptsnot yet published, although preliminary data have been recently presented ${ }^{18}$-addressing recommendation of symptomatic and general treatment as well as on treatment of specific complications (muscular, peripheral and central nervous system, haematological) included or not included in the EULAR SS Disease Activity Index (ESSDAI) and lymphoproliferative disease. The same EULAR SS task force has elaborated a consensus set of recommendations that aid in the establishment of an early diagnosis of primary SS. ${ }^{15}$ They provide a homogeneous diagnostic approach to the patients with suspected primary SS based on the clinical presentation pattern, and specifically those presenting with systemic involvement.

Two papers arising from the patient organisation Sjögren's Syndrome Foundation (SSF) effort of developing CPG for SS, approach the management of specific ocular $^{16}$ and oral ${ }^{17}$ dryness and its complications. Foulks et al provide a broad review of the evaluation (symptoms and signs/tests of tear function) and treatment (topical/ systemic treatments and other approaches) of SS-associated dry eye and emit recommendations on these areas, 
Table 1 Currently available evidence-based medicine clinical practice guidelines on diagnosis and management of SS

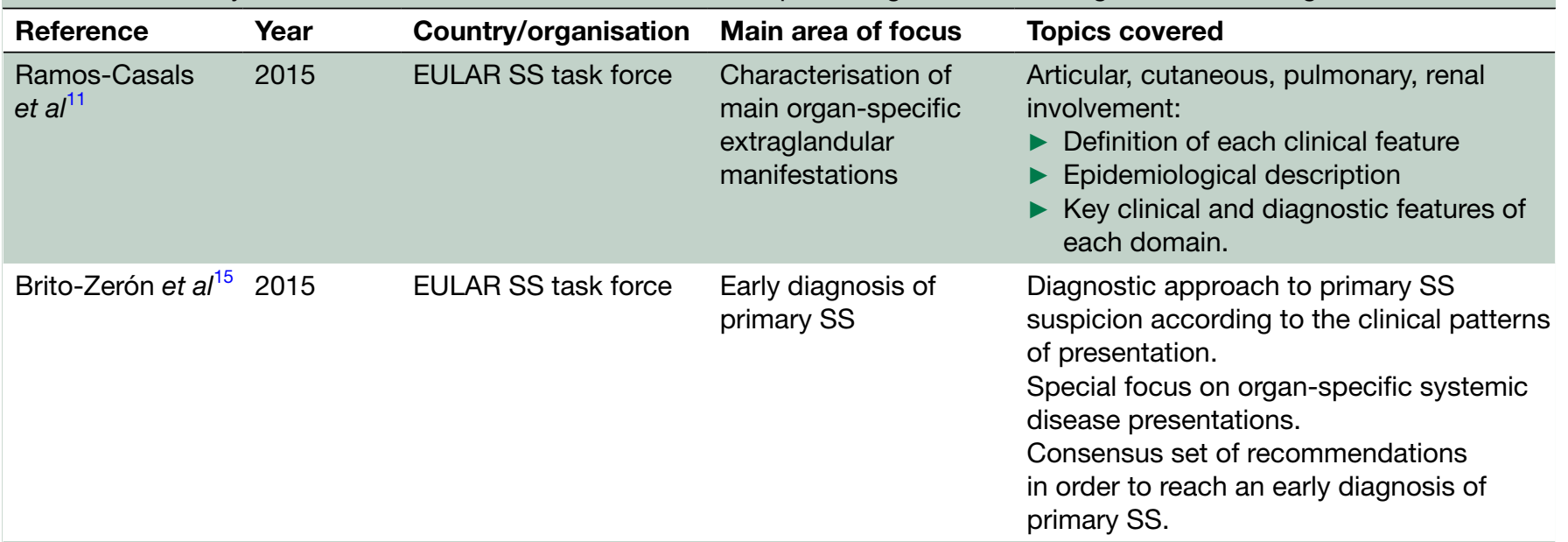

\begin{tabular}{|c|c|c|c|c|}
\hline Foulks et $a l^{16}$ & 2015 & $\begin{array}{l}\text { USA/Sjögren's } \\
\text { Syndrome Foundation }\end{array}$ & $\begin{array}{l}\text { Management of dry eye } \\
\text { associated with SS }\end{array}$ & $\begin{array}{l}\text { Evaluation of dry eye disease in SS: } \\
\text { symptom evaluation and diagnostic } \\
\text { testing. } \\
\text { Treatment of dry eye disease in SS: } \\
\text { algorithm based on severity level and } \\
\text { response to therapy. }\end{array}$ \\
\hline Zero et $a l^{17}$ & 2016 & $\begin{array}{l}\text { USA/Sjögren's } \\
\text { Syndrome Foundation }\end{array}$ & $\begin{array}{l}\text { Management of oral } \\
\text { complications of SS }\end{array}$ & Strategies for caries prevention in SS. \\
\hline Carsons et $a l^{12}$ & 2016 & $\begin{array}{l}\text { USA/Sjögren's } \\
\text { Syndrome Foundation }\end{array}$ & $\begin{array}{l}\text { Treatment of } \\
\text { rheumatological } \\
\text { manifestations of SS }\end{array}$ & $\begin{array}{l}\text { Biological therapy for sicca/systemic } \\
\text { manifestations. } \\
\text { Treatment and management of fatigue. } \\
\text { csDMARDs for inflammatory } \\
\text { musculoskeletal pain. }\end{array}$ \\
\hline Valim et $a^{13}$ & 2015 & $\begin{array}{l}\text { Brazil/Brazilian Society } \\
\text { of Rheumatology }\end{array}$ & Treatment of SS & $\begin{array}{l}\text { General measures and patient education. } \\
\text { Symptomatic management of dryness. } \\
\text { Systemic treatment of glandular and } \\
\text { systemic manifestations of SS. }\end{array}$ \\
\hline Price et $a l^{14}$ & 2017 & $\begin{array}{l}\text { UK/British Society of } \\
\text { Rheumatology }\end{array}$ & $\begin{array}{l}\text { Management of } \\
\text { dryness and systemic } \\
\text { disease in adults with } \\
\text { primary SS }\end{array}$ & $\begin{array}{l}\text { Management of dryness (ocular, oral, } \\
\text { systemic). } \\
\text { Management of fatigue and systemic } \\
\text { disease. } \\
\text { Management of pregnancy. } \\
\text { Risk assessment and monitoring of } \\
\text { lymphoma. }\end{array}$ \\
\hline
\end{tabular}

csDMARDs, conventional synthetic disease-modifying antirheumatic drugs; EULAR, European League Against Rheumatism; SS, Sjögren's syndrome.

including a treatment algorithm based on severity level and response to therapy. ${ }^{16}$ Zero et al developed EBM recommendations for patients with SS who were with dry mouth, specifically focusing on caries prevention measures. ${ }^{17}$

Treatment of dryness, fatigue and systemic involvement has been addressed in three different sets of high-quality recommendations proposed by European (UK) ${ }_{13}^{14}$ North American (SSF) ${ }^{12}$ and South American (Brazil) ${ }^{13}$ organisations. As part of the SSF initiative mentioned above, Carsons et al have systematically reviewed available literature and proposed treatment recommendations in three specific areas: biological therapy for sicca and systemic manifestations; management of fatigue and use of conventional synthetic disease-modifying antirheumatic drugs
(csDMARDs) for inflammatory musculoskeletal pain. ${ }^{12}$ Valim et al developed treatment guidelines, sponsored by the Brazilian Society of Rheumatology, covering a broad range of topics: general and patient education measures, including references on exercise, vaccination and vitamin D supplementation; symptomatic management of dryness (oral, ocular and other); systemic treatment of glandular and extraglandular manifestations, including csDMARDs and biologics, and treatment according to organ-specific involvement. ${ }^{13}$ The British Society of Rheumatology has also recently produced National Institute for Clinical Excellence-accredited CPGs for the management of adults with primary SS. ${ }^{14}$ This paper provides comprehensive recommendations covering the treatment of primary SS in its several dimensions: dryness (ocular, oral 
and other), salivary gland enlargement, fatigue and use of csDMARDs and biologics for systemic disease. Moreover, it addresses briefly the management of pregnancy in female patients with SS and lymphoma risk assessment and monitoring.

\section{Potential gaps in current existing CPGs}

We have identified a few potential gaps in current existing guidelines. Several key aspects regarding applicability, implementation (costs/resources) and monitoring/update plan of guidelines are generally missing in most available recommendations. This is important as the application of recommendations in clinical practice can be limited by local practices and rules (eg, cost, availability or approved indication of a given drug), that should thus be taken into account. A plan for monitoring the application and updating the guidelines should also be added, as per the best guidance on guideline elaboration methodology. We also consider that a better dissemination plan is needed for the current available guidelines, and that in some cases, the translation and/ or adoption of these guidelines by other European countries would be helpful. Moreover, as mentioned above, a significant number of recommendations covering several areas of SS management and diagnosis are mostly based on expert consensus, considering the lack of randomised controlled trials (RCTs) and high-quality observational studies for SS-related specific questions. Finally, it should be noted that $3 / 7$ of the cited CPGs did not include patients' representatives in the working panel, a relevant aspect that needs to be taken into account when generating CPGs.

\section{Other important tools and resources}

Despite not constituting the main aim of the present SLR, a number of other tools and resources important in SS clinical practice were identified and deserve mention. International collaborations have successfully led to the creation of classification criteria for SS that have been widely used in the past two decades, of which the most commonly employed are the American European Consensus Group 2002 criteria $^{19}$ and the preliminary American College of Rheumatology (ACR) 2012 criteria. $^{20}$ Recently, ACR and EULAR have joined efforts to develop a single set of data-driven consensus classification criteria for primary SS, that may replace the former. ${ }^{21}$ Importantly, these classification criteria are primarily oriented for enrolment of patients in clinical trials, although being frequently used for guiding diagnosis in clinical practice.

In the past decade, the EULAR SS task force committed to developing clinical tools that reflect the complex nature of SS. From this initiative, important instruments have emerged, including the ESSDAI, ${ }^{22}$ which assesses systemic disease activity in its several domains, and the EULAR SS Patient Reported Index (ESSPRI), ${ }^{23}$ which translates the most common symptoms reported by patients (pain, dryness, fatigue). These indexes have been posteriorly complemented with a very useful user guide ${ }^{24}$ definitions of disease activity states and clinically meaningful improvement ${ }^{25}$ and a simpler, clinical only version. ${ }^{26}$ This comprehensive effort has resulted in the fast and widespread incorporation of these tools in clinical practice and research, significantly improving care of patients with SS. Together with pre-existent resources for evaluating and scoring damage developed by European groups, ${ }^{27}{ }^{28}$ they have successfully contributed for a global overview of the impact of SS at the individual patient level.

Other important resources including guidance and recommendations for key areas like salivary gland biopsy $^{29}$ and ultrasound ${ }^{30}$ and a list of patient organisations devoted to SS are available at the SS disease info toolbox of the ERN-ReCONNET website. ${ }^{31}$

\section{UNMET NEEDS}

Despite considerable advances in recent years regarding the development of CPGs specific for SS that decisively contribute to improving care of patients with SS, a key point common to most recommendations is that they are frequently supported by low-to-moderate quality evidence and strongly rely on expert opinion. Indeed, there is a major need for high-quality studies in several areas of SS diagnosis and management in order to further support or modify currently available guidelines. ${ }^{32}$ The most important unmet need is the ability or not to recommend, in all patients or in a subgroup of patients, a DMARD able to change the evolution of the disease. For achieving this aim, it is crucial to pursue RCTs that have begun in this disease and that recently yielded for the first time a positive result, in a phase 2 RCT with an anti-CD40 monoclonal antibody. ${ }^{33}$

Historically, despite its considerable prevalence among CTDs, SS has been devoted much less research interest, time and effort compared with other close conditions, such as rheumatoid arthritis, systemic lupus erythematosus or vasculitides. ${ }^{1}$ As such, clinical approach of SS has often mirrored the experience with these other CTDs, for which evidence is strongly supported by robust clinical trials and large observational studies. Regardless of the obvious similarities with some of these diseases, SS is a heterogeneous condition, with different clusters of patients defined by typical manifestations and symptoms and, therefore, a uniform response is unlikely to be seen with most treatments. This underlines the need for designing large studies, with several patient subgroups and patient's stratifications, aiming to demonstrate the efficacy of csDMARDs, glucocorticoids, biologics and novel molecules specifically in SS.

For this matter, active and synergistic involvement of patients, clinicians and scientists in the definition of unmet needs and areas of future research in SS is crucial. Hopefully, these efforts will help to set the path for the elaboration of comprehensive high-quality CPGs, supported by a larger body of evidence, which will decisively contribute 
to improve and standardise SS patient care. In this regard, it is reassuring to learn that patient and scientific organisations such as SSF and EULAR have planned to develop additional CPGs covering other important questions, which should become available soon. ${ }^{112}$

\section{Clinicians' unmet needs}

Guidelines proposing a systematic diagnostic approach of SS are needed, if possible mostly supported by solid data (vs expert consensus). This includes SS in general, and organ-specific manifestations not already covered by the available CPGs. A specific focus should be given to the use/usefulness and standardisation of diagnostic tools, including key ones such as minor salivary gland biopsy and salivary gland ultrasound and others with potentially less current impact like salivary gland scintigraphy and sialography.

Regarding treatment, as mentioned, there is an important unmet need to be able to recommend, or not, a DMARD that definitely changes the evolution of the disease in all patients or in a subgroup of patients. Thorough treatment guidance on each specific organ involvement and clear definitions of response/non-response, supported by SS studies, are warranted. Importantly, EBM recommendations for screening, identification and monitoring of patients at high risk of developing haematological malignant disorders (most importantly non-Hodgkin's lymphoma) are also missing. Other important areas to be addressed by future guidelines include: evaluation/approach to cardiovascular risk; immunisation strategies of patients with SS; planning and management of pregnancy in patients with SS and strategies for assessment of patient burden and SS-related quality of life.

A number of unmet needs still exist for the disease and patients and significant efforts should be placed in order to identify effective symptomatic and systemic therapies and biomarkers for stratifying patients, predicting disease activity/severity and response to treatment. Validation of data arising from small studies should be performed in powerful clinical trials, and for that matter, development of tools that adequately capture the full picture of the disease and are sensitive to change is vital. The same applies to evidence imported from other CTDs, that should be replicated in patients with SS. Initiatives like the ongoing HarmonicSS project will contribute towards these aims, through the development of learning tools to expand the knowledge of SS for both clinicians and patients. $^{34}$

Regarding patient-reported outcomes (PRO), several aspects have to be developed. The ESSPRI score has the big advantage of being very simple and thus doable in less than 1 min during any patient consultation, but it is probably too reductive. Several aspects of fatigue (mental or physical), limb pain (musculoskeletal, neurological or fibromyalgia-like) and dryness should be developed. Likewise, personal patients' applications for measuring PRO more frequently (ie, on a weekly basis) should be developed and, indeed, this is one of the tasks of the NECESSITY Innovative Medical Initiative project in preparation from the European Commission.

\section{Patients' unmet needs}

This paragraph intends to highlight the unmet needs of the Sjögren's Syndrome European community. The content of this paragraph has been realised by the ERN ReCONNET European Patient Advocacy Group that carefully collected the voices and the points of view of the whole European community of the disease they represent.

Finding a physician that understands Sjögren is still a big challenge nowadays, and this is probably the underlying cause of the most prevalent reported unmet need: delay to diagnosis. Patients are often dismissed because doctors can't relate symptoms, or they are not taken seriously. Consequently, lack of understanding from family, friends and employers paves the way to a heavy emotional burden, not to mention disease progression-related issues.

Besides early diagnosis, delay to treatment is the second most widespread unmet need. It's not clear if doctors don't know how to treat Sjögren's or if it's seen exclusively as a dry eyed and dry mouth disease. Whether we need combination therapies or new therapeutic targets, the fact is effective and specific treatment lacks, and treatments for Sjögren are largely symptomatic. Sjögren's has been an orphan disease in what concerns to specific drugs approval, so establishing rational targets for drug development is a must. Being a highly heterogenous disease, even at molecular level, shows the need for stratification and tailored treatment strategy. In this concern, genetics must be understood as it seems to play an important role.

Fatigue, pain and cognitive dysfunction, often seen as "benign features", are the cause of greatest patient-reported disability. Understanding how these symptoms truly impact patients' lives and clarifying if depression results from disease activity, or is fatigue related, is a big challenge that urgently needs to be addressed. Disease self-management programme-patient education; lifestyle guidelines-along with non-pharmacological approaches-exercise; meditation; occupational therapies-are interesting resources that lack to be explored and can be key to restore quality of life. There's life beyond the disease and patients deserve to live it at its fullest, but they need to be empowered to know how to manage it in all circumstances.

Finally, more reliable information is needed to address the lack of knowledge from HCPs, public, family, friends and employers.

\section{CONCLUSIONS}

In the last years, a number of good quality EBM recommendations on diagnosis and management of SS have been published by national and international 
organisations. Importantly, patients have been taking an active role and joining clinicians to develop CPGs and define important areas of future research and unmet needs.

However, there is still a need for robust studies addressing several key aspects of SS diagnosis and treatment to serve as basis for high-quality EBM guidelines, which should be implemented across Europe and updated regularly. There is a major gap concerning specific therapies, predictors and biomarkers for SS that may contribute to significantly improve the outcome of patients affected by this disease.

Initiatives such as the present one, involving patients and experts in multicentre consortiums, contribute to raising awareness for complex diseases such as SS and to defining key areas of development, ultimately leading to improved patient care.

\section{Author affiliations}

${ }^{1}$ Rheumatology Department, Hospital de Santa Maria, Centro Hospitalar Lisboa Norte, Lisbon, Portugal

${ }^{2}$ Rheumatology Unit, AOU Pisana, Pisa, Italy

${ }^{3}$ Section of Rheumatology, Department of Medical Sciences, University of Ferrara, Ferrara, Italy

${ }^{4}$ Núcleo Síndrome de Sjögren, Liga Portuguesa Contra as Doenças Reumáticas, Lisbon, Portugal

${ }^{5}$ Department of Rheumatology and Clinical Immunology, Charité University Hospital Berlin, Berlin, Germany

${ }^{6}$ Rheumatology Unit, University of Pisa, Pisa, Italy

${ }^{7}$ Service de rhumatologie, Hôpitaux Universitaires de Strasbourg, Centre National de Référence des Maladies Systémiques et Auto-immunes Rares Grand-Est Sud-0uest (RES0), INSERM-UMRS 1109, F-67000, Strasbourg, France

${ }^{8}$ Unidade de Doenças Auto-imunes, Medicina 7.2, Hospital Curry Cabral, Centro Hospitalar de Lisboa Central, Lisbon, Portugal

${ }^{9}$ Département de Médecine Interne et Immunologie Clinique, Centre de Référence des Maladies Systémiques et Auto-Immunes Rares du Nord-Ouest (CERAINO), LIRIC, INSERM, Univ. Lille, CHU Lille, Lille, France

${ }^{10}$ Service de Médecine Interne, Hôpital Cochin, Centre de Référence Maladies systémiques Autoimmunes Rares d'lle de France, Assistance Publique-Hôpitaux de Paris (AP-HP), Université Paris Descartes, Paris, France

${ }^{11}$ Department of Clinical and Experimental Medicine, Division of Rheumatology and Scleroderma Unit, AOU Careggi, University of Florence, Florence, Italy

${ }^{12}$ Department of Rheumatology, Emergency County Teaching Hospital, Cluj-Napoca, Romania

${ }^{13}$ Service de Médecine Interne 2, Hôpital La Pitié-Salpêtrière, Institut E3M,

Sorbonne Université, Assistance Publique-Hôpitaux de Paris, Paris, France

${ }^{14}$ Rheumatology and Clinical Immunology Unit, ASST Spedali Civili di Brescia, Brescia, Italy

${ }^{15}$ Department of Allergology, Rheumatology and Clinical Immunology, University Children's Hospital, University Medical Centre Ljubljana, Ljubljana, Slovenia

${ }^{16}$ Department of Internal Medicine and Immunology, Erasmus MC, Rotterdam, The Netherlands

${ }^{17}$ Department of Rheumatology and Clinical Immunology, University Medical Center Utrecht, Utrecht University, Utrecht, The Netherlands

${ }^{18}$ University of Pisa, Pisa, Italy

${ }^{19}$ Department of Rheumatology, Universitätsklinikum Düsseldorf, Düsseldorf, Germany

${ }^{20}$ Department of Rheumatology and Department of Internal Medicine, Ghent University Hospital, Ghent, Belgium

${ }^{21}$ Research Laboratory and Academic Division of Clinical Rheumatology, Department of Internal Medicine, IRCCS Polyclinic Hospital San Martino, University of Genoa, Genoa, Italy

${ }^{22}$ Université Paris-Sud: AP-HP, Hôpitaux Universitaires Paris-Sud; INSERM UMR 1184, Le Kremlin Bicêtre, France
Acknowledgements Thanks to all the members of the Steering Committee of the ERN ReCONNET for the huge commitment during this work. A special thank goes to all the members of the ERN ReCONNET team for providing support during all the phases of the Work Package 3 .

Contributors VCR, RT, CAS, AV, XM: substantial contributions to the conception and design of the work, the acquisition, analysis and interpretation of data; drafting the work and revising it critically for important intellectual content; final approval of the version to be published; agreement to be accountable for all aspects of the work in ensuring that questions related to the accuracy or integrity of any part of the work are appropriately investigated and resolved. TA, CB, J-EG, HG, LM, MO, CP, MP, MT, TN, JMV, PV: substantial contributions to the analysis and interpretation of data; final approval of the version to be published; agreement to be accountable for all aspects of the work in ensuring that questions related to the accuracy or integrity of any part of the work are appropriately investigated and resolved. EH: revising the work critically for important intellectual content; substantial contributions to the analysis and interpretation of data; final approval of the version to be published; agreement to be accountable for all aspects of the work in ensuring that questions related to the accuracy or integrity of any part of the work are appropriately investigated and resolved. SB, MC, MM: substantial contributions to the conception and design of the work, the acquisition, analysis and interpretation of data; revising the work critically for important intellectual content; final approval of the version to be published; agreement to be accountable for all aspects of the work in ensuring that questions related to the accuracy or integrity of any part of the work are appropriately investigated and resolved. MS, VS: revising the work critically for important intellectual content; final approval of the version to be published; agreement to be accountable for all aspects of the work in ensuring that questions related to the accuracy or integrity of any part of the work are appropriately investigated and resolved.

Funding This publication was funded by the European Union's Health Programme (2014-2020).

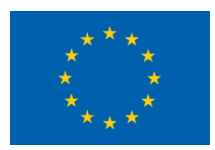

Disclaimer ERN ReCONNET is one of the 24 European Reference Networks (ERNs) approved by the ERN Board of Member States. The ERNs are co-funded by the European Commission. The content of this publication represents the views of the authors only and it is their sole responsibility; it cannot be considered to reflect the views of the European Commission and/or the Consumers, Health, Agriculture and Food Executive Agency (CHAFEA) or any other body of the European Union. The European Commission and the Agency do not accept any responsibility for use that may be made of the information it contains.

Competing interests None declared.

Patient consent Not required.

Provenance and peer review Commissioned; externally peer reviewed.

Data sharing statement № additional data are available.

Open access This is an Open access article distributed in accordance with the Creative Commons Attribution Non Commercial (CC BY-NC 4.0) license, which permits others to distribute, remix, adapt, build upon this work non-commercially, and license their derivative works on different terms, provided the original work is properly cited, appropriate credit is given, any changes made indicated, and the use is non-commercial. See: http://creativecommons.org/licenses/by-nc/4.0/.

\section{REFERENCES}

1. Mariette X, Criswell LA. Primary Sjögren's Syndrome. N Engl J Med 2018;378:931-9.

2. Brito-Zerón $\mathrm{P}$, Baldini $\mathrm{C}$, Bootsma $\mathrm{H}$, et al. Sjögren syndrome. Nat Rev Dis Primers 2016;2:16047.

3. Saraux A, Pers JO, Devauchelle-Pensec V. Treatment of primary Sjögren syndrome. Nat Rev Rheumatol 2016;12:456-71.

4. Nocturne G, Cornec D, Seror R, et al. Use of biologics in Sjögren's syndrome. Rheum Dis Clin North Am 2016;42:407-17.

5. Héon-Klin V. European Reference networks for rare diseases: what is the conceptual framework? Orphanet J Rare Dis 2017;12:137.

6. European Commission. European reference networks internet. Available from: https://ec.europa.eu/health/ern/overview_en [accessed 23 Jun 2018].

7. ERN ReCONNET. European reference network on rare and complex connective tissue and musculoskeletal diseases [Internet]. Available from: http://reconnet.ern-net.eu/ [accessed 23 Jun 2018].

8. Institute of Medicine (U.S.). Clinical practice guidelines we can trust. Washington, DC: National Academies Press, 2011.

9. Brouwers MC, Kho ME, Browman GP, et al. AGREE II: advancing guideline development, reporting and evaluation in health care. CMAJ 2010;182:E839-42. 
10. Moher D, Liberati A, Tetzlaff J, et al. Preferred reporting items for systematic reviews and meta-analyses: the PRISMA statement. PLoS Med 2009;6:e1000097.

11. Ramos-Casals M, Brito-Zerón P, Seror R. Characterization of systemic disease in primary Sjögren's syndrome: EULAR-SS task force recommendations for articular, cutaneous, pulmonary and renal involvements. Rheumatology 2015;28:kev200.

12. Carsons SE, Vivino FB, Parke A, et al. Treatment guidelines for rheumatologic manifestations of Sjögren's syndrome: use of biologic agents, management of fatigue, and inflammatory musculoskeletal pain. Arthritis Care Res 2017;69:517-27.

13. Valim V, Trevisani VF, Pasoto SG, et al. Recommendations for the treatment of Sjögren's syndrome. Rev Bras Reumatol 2015;55:446-57.

14. Price EJ, Rauz S, Tappuni AR, et al. The British society for rheumatology guideline for the management of adults with primary Sjögren's syndrome. Rheumatology 2017;56:1828.

15. Brito-Zerón P, Theander E, Baldini C, et al. Early diagnosis of primary Sjögren's syndrome: EULAR-SS task force clinical recommendations. Expert Rev Clin Immunol 2016;12:137-56.

16. Foulks GN, Forstot SL, Donshik PC, et al. Clinical guidelines for management of dry eye associated with Sjögren disease. Ocul Surf 2015;13:118-32.

17. Zero DT, Brennan MT, Daniels TE, et al. Clinical practice guidelines for oral management of sjögren disease: dental caries prevention. $J$ Am Dent Assoc 2016;147:295-305.

18. Retamozo S. SP0159 Eular recommendations for the management of sjÖgren's syndrome. Ann Rheum Dis 2018;77:42.

19. Vitali C, Bombardieri S, Jonsson R, et al. Classification criteria for sjögren's syndrome: a revised version of the European criteria proposed by the American-European consensus group. Ann Rheum Dis 2002;61:554-8.

20. Shiboski SC, Shiboski CH, Criswell LA, et al. American college of rheumatology classification criteria for Sjögren's syndrome: a data-driven, expert consensus approach in the sjögren's international collaborative clinical alliance cohort. Arthritis Care Res 2012;64:475-87.

21. Shiboski CH, Shiboski SC, Seror R, et al. 2016 American College of Rheumatology/European League Against Rheumatism Classification Criteria for Primary Sjögren's Syndrome: A Consensus and DataDriven Methodology Involving Three International Patient Cohorts. Arthritis Rheumatol 2017:69:35-45.

22. Seror R, Ravaud P, Bowman SJ, et al. EULAR Sjogren's syndrome disease activity index: development of a consensus systemic disease activity index for primary sjogren's syndrome. Ann Rheum Dis 2010;69:1103-9.
23. Seror R, Ravaud P, Mariette X, et al. EULAR Sjogren's syndrome patient reported index (ESSPRI): development of a consensus patient index for primary Sjogren's syndrome. Ann Rheum Dis 2011;70:968-72.

24. Seror R, Bowman SJ, Brito-Zeron P, et al. EULAR Sjögren's syndrome disease activity index (ESSDAI): a user guide. RMD Open 2015:1:e000022.

25. Seror R, Bootsma H, Saraux A, et al. Defining disease activity states and clinically meaningful improvement in primary Sjögren's syndrome with EULAR primary Sjögren's syndrome disease activity (ESSDAl) and patient-reported indexes (ESSPRI). Ann Rheum Dis 2016;75:382-9.

26. Seror R, Meiners P, Baron G, et al. Development of the clinESSDAl: a clinical score without biological domain. A tool for biological studies. Ann Rheum Dis 2016;75:1945-50.

27. Vitali C, Palombi G, Baldini C, et al. Sjögren's syndrome disease damage index and disease activity index: scoring systems for the assessment of disease damage and disease activity in Sjögren's syndrome, derived from an analysis of a cohort of italian patients. Arthritis Rheum 2007;56:2223-31.

28. Barry RJ, Sutcliffe N, Isenberg DA, et al. The Sjögren's syndrome damage index--a damage index for use in clinical trials and observational studies in primary sjögren's syndrome. Rheumatology 2008:47:1193-8.

29. Fisher BA, Jonsson R, Daniels T, et al. Standardisation of labial salivary gland histopathology in clinical trials in primary sjögren's syndrome. Ann Rheum Dis 2017;76:1161-8.

30. Jousse-Joulin S, Nowak E, Cornec D, et al. Salivary gland ultrasound abnormalities in primary Sjögren's syndrome: consensual US-SG core items definition and reliability. RMD Open 2017;3:e000364.

31. ERN-ReCONNET Disease Info Toolbox (SS). Available from: http:// reconnet.ern-net.eu/disease_SS/\#1528108857968-34c0017f-022e

32. Winthrop KL, Strand V, van der Heijde $D$, et al. The unmet need in rheumatology: reports from the targeted therapies meeting 2017. Clin Immunol 2018;186:87-93.

33. Fisher B, Zeher M, W-F N. The novel anti-CD40 monoclonal antibody CFZ533 shows beneficial effects in patients with primary sjögren's syndrome: a phase iia double-blind, placebo-controlled randomized trial. Arthritis \& Rheumatology;69:2538.

34. HarmonicSS. HARMONIzation and integrative analysis of regional, national and international Cohorts on primary Sjögren's Syndrome (pSS) towards improved stratification, treatment and health policy making. Available from: http://harmonicss.eu/ [accessed 27 Jun 2018] 